\title{
О РОЛИ И ЗНАЧЕНИИ ТАМОЖЕННОГО СОТРУДНИЧЕСТВА В ОБЕСПЕЧЕНИИ ЕВРОПЕЙСКОЙ ЭКОНОМИЧЕСКОЙ ИНТЕГРАЦИИ
}

\author{
(c) 2020 ДитцД.А. \\ старший преподаватель, аспирант \\ Российская таможенная академия, Россия, Люберцы
}

Международная экономическая интеграция является результатом продуктивного межгосударственного сотрудничества в торгово-экономической сфере. Таможенное сотрудничество является специализированной областью международного взаимодействия органов государственной власти, которое позволяет таможенным службам скоординировано решать как текущие, так и перспективные задачи, касающиеся таможенного оформления, контроля, регулирования, правоохранительной деятельности. При этом международное таможенное сотрудничество обеспечивает развитие международной торговли в соответствии с международно-правовыми нормами и рекомендациями, требованиями внутреннего законодательства государств. Международная экономическая интеграция в различных формах изначально начала развиваться благодаря торговым отношениями как между отдельными городами, так и государствами, о чем свидетельствует европейский опыт. Таможенное сотрудничество выступало и как предоставление определенных преференций в случае развития торговли между городами и укрепления межгосударственных отношений, и как таможенный союз, создание которого является важнейшим этапом развития интеграционного объединения.

Ключевые слова: международная экономическая интеграция, таможенное обеспечение, международное таможенное сотрудничество, таможенный союз, рационализм, рациональное экономическое поведение, ресурсный потенциал, экономическая интеграция в Европе, международная торговля.

Таможенное обеспечение международной экономической интеграции является процессом производным от таможенного сотрудничества в различных формах, несет при этом значительные социально-экономические смысл и функции. Обеспечение предполагает с одной стороны определенные действия для достижения поставленных целей, с другой стороны, наличие необходимых для осуществления данных действий административных, финансовых, материальных ресурсов, а также определенные гарантии либо решения конкретных задач, либо наличия финансовых, материальных, нематериальных и других ресурсов в распоряжении компетентного центра ответственности. В качестве обеспечивающего субъекта (центра ответственности) может выступать государство в лице органов исполнительной власти, интеграционное объединение, международная организация, отдельные предприятия и организации, международные компании в различных организационно-правовых формах.

Как правило процесс обеспечения прямо или косвенно связан с финансово-хозяйственной деятельностью, имея экономическую природу. Вместе с тем целесообразно выделять эконо- мическое обеспечение в отдельную категорию. Экономическое обеспечение представляет собой комплекс гарантированных действий субъекта финансово-хозяйственных отношений по созданию, приобретению и предоставлению материальных и нематериальных, финансовых активов другим субъектам для достижения совместно определенных субъектами целей, решения поставленных задач.

В общем смысле целью обеспечения является обеспеченность материальными или нематериальными активами, которая в свою очередь определяет то, насколько возможно достижение других, текущих, перспективных или стратегических целей.

С экономической точки зрения обеспеченность каким-либо ресурсом напрямую связана с его ограниченностью, демонстрируя прямую зависимость: чем выше степень ограниченности ресурса, тем выше потребность в обеспеченности данным ресурсом. Экономическая обеспеченность представляет собой в данном случае удовлетворенную потребность субъекта в определенном ресурсе.

Нулевая гипотеза об обеспеченности определенным видом экономического ресурса мо- 
жет быть подтверждена на основании статистических показателей, динамики показателей. Как, например, «обеспеченность города землями отношение общего размера городской территории и ее отдельных категорий к численности постоянного населения города, обеспеченность города энергетическим хозяйством определяется сопоставлением распределительной сети города (электрической, газовой, теплофикационной) по оси улиц с общей протяженностью всех улиц города» [1].

Зарождение и становление международной экономической интеграции в Европе исторически изначально было связано с потребностью в различных обеспеченностях городов. Европейская экономическая интеграция в ее первых формах была скорее экономической интеграцией городов в связи с тем, что развитие различных видов экономических потребностей, потребительского рынка происходило с развитием производительных сил в европейских городах и с ростом городского населения.

В этой связи особый интерес представляют собой «ганзейские союзы», которые возникли и получили свое развитие в ряде европейских регионов. Одним из первых стал союз, объединивший в себя представителей купечества Гамбурга и Любека, возникший в середине XII века, и заложивший основы будущего «ганзейского союза» [2].

Предметом первых договоренностей купцов конечны были вопросы внешней торговли, которые находятся в непосредственной взаимосвязи с вопросами таможенного регулирования. Поэтому появление первых признаков «ганзейских союзов» как союзов в сфере торговли, является и признаками зарождения международных таможенных отношений, международного таможенного сотрудничества. Применительно к «ганзейским союзам» с точки зрения реализации купцами своей по сути внешнеторговой политики того времени следует вести речь как об одной из первых форм торгово-экономической интеграции, которая возникла в результате взаимодействия отдельных социально и экономически значимых городов. С другой стороны, международного таможенное сотрудничество, которое обнаружило себя в виде определенного рода взаимных таможенных преференций, предоставляемых сначала торгующим сословием, а затем городами друг другу, стало на первых этапах отражать стремление к должному таможенному обеспечению развиваемых внешней торговли и экономической интеграции. В последствии международное таможенное сотрудничество трансформируется в значительный инструмент реализации государственной внешней политики, профильную компетенцию интеграционных институтов, международных организаций.

На примере начала деятельности «ганзейских союзов» наблюдается стремление европейских городов к обеспеченности торговоэкономическими и таможенными ресурсами с целью поддержания и роста благосостояния, удовлетворения как личных, так и общественных потребностей. Как финансовые-хозяйственные, торговые, так и таможенные инструменты становятся частью ресурсного потенциала, к укреплению которого стремились как европейские города, так и европейские государства в целом.

В этой связи развитие экономической интеграции и международного таможенного сотрудничества в форме «ганзейских союзов», являясь историческим фактом, было объективно и неизбежно в силу необходимости, постоянного стремления восполнить недостающие ресурсы, а также создать достаточный потенциал для дальнейшего экономического развития.

Содержание и смысл категории «потенциал» в достаточной степени объясняют все объединительные тенденции прошлого и современности в различных сферах. «Потенциал (от лат. potentia - сила, мощь) - совокупность имеющихся средств, возможностей в какой-либо области» [3], например, совокупность экономических ресурсов. Если спроецировать содержание понятие потенциала из естественно-научной области, то это «величина, которая характеризует силовое поле в данной точке, а разность потенциалов между двумя точками поля определяет работу, которое совершит пробное тело при движении из одной точки в другую» [3]. Именно в разности потенциалов городов, государств, в различной обеспеченности их ресурсами, разным наличием товаров на рынках, заложены предпосылки к началу и развитию между ними торговли, экономической интеграции. То есть разность потенциалов двух точек (городов, государств) создает силовое поле (международный рынок), на котором определяется работа (движение) определенного тела (товара или группы товаров), подчиняясь при этом определенным правилам прохождения таможенного контроля и таможенного оформления, которые призваны 
обеспечить законность, стабильность и доходность для государств совершаемых международных торговых сделок.

Государства, которые в разной степени наделены теми или иными ресурсами, находятся на относительно разных уровнях экономического развития, тяготеют к развитию взаимного товарооборота и процесс этот закономерен, получивший свое начало от торговли между отдельными хозяйствующими субъектами (купцами), находящимися в разных юрисдикциях (городах). Таможенное сопровождение данной деятельности, которое кроме всего прочего выполняет определенную фискальную и социально-экономическую функцию, является способом и формой осуществления волеизъявления, контроля и управления данными процессами. И использование таможенного механизма при этом неизбежно изначально, поскольку данный механизм является частью ресурсного потенциала государства, административным потенциалом в лице таможенных служб, деятельность которых напрямую связана с вопросами контроля, оформления и регулирования международных торговых операций.

Категория «потенциал» в сущности является производной от категории «потентат» (от лат. potentatus - верховная власть) [3]. Таможенное обеспечение внешнеторговых операций, как один из инструментов реализации государственной власти, является частью ресурсного потенциала, источником пополнения бюджета, средством защиты экономических интересов государств или их объединений.

Ресурсный потенциал не может иметь перманентного состояния, находясь под влиянием ряда факторов, кроме этого, требует рационального поведения от субъектов, его формирующих и стремящихся к его сохранению, укреплению и развитию. В свое очередь иррациональное поведение может приводить к сокращению потенциала, либо его утрате, если исходить из позиций рационализма. При этом стремление к сохранению ресурсного потенциала, к обеспечивающему его рациональному поведению также имеет свою основу, которая сводится к обеспечению экономической составляющей безопасности - экономической безопасности, защите и укреплению экономического суверенитета. Экономический рационализм, рациональное экономическое поведение являются естественной и неизбежной моделью жизнедеятельности любого общества в стремлении к безопасности и независимости, удовлетворению потребностей. Механизм функционирования органов государственной власти в этой связи являются наиболее эффективной и действенной системой инструментов, позволяющей в законном порядке обеспечить экономическую рациональность. Таможенное дело является неотъемлемой частью данного инструментария государственного обеспечения экономических рациональности, безопасности, суверенитета, удовлетворения потребностей государства и населения.

Появление и развитие международной экономической интеграции связаны со стремлением общества, государств к рациональному экономическому поведению. Обеспечивающая функция таможенного дела в сфере экономической интеграции сводится к обеспечению рационального экономического поведения. Таможенное обеспечение рационального экономического поведения является обязательным элементом системы государственного управления. Природа международной экономической интеграции заключается в стремлении государств к рациональному экономическому поведению.

Рациональное экономическое поведение может стремиться к бесконечности по причине того, что обусловлено кроме потребности к экономической безопасности и укреплению экономического суверенитета, стремлением к удовлетворению общественных потребностей и максимизации дохода. В свою очередь, как содержание и пределы общественных потребностей, так и представление о приемлемой норме дохода могут трансформироваться в зависимости от мировой экономической, политической конъюнктуры и международной обстановки, и в итоге стремиться к бесконечности.

Нижний предел рационального экономического поведения понятен и обусловлен соотношением доходов и расходов. Верхний предел рационального экономического поведения находится в плоскости представления о максимизации дохода, как о категории постоянно стремящейся к бесконечности.

Поскольку интеграционные процессы - это выражение постоянного стремления государств к развитию своего рационального экономического поведения, нижние пределы характерны и для международной экономической интеграции, и определяются той группой стран, которые инициируют экономическую интеграцию и со- 
храняют при этом в процессе развития сбалансированное соотношение процессов углубления и расширения финансово-экономических и торговых связей.

Применительно к верхним пределам интеграционных процессов практика европейской экономической и политической интеграции свидетельствует о том, что деструктивные тенденции могут иметь место в силу комплекса внутренних и внешних факторов. Верхние пределы экономической интеграции могут иметь вполне четкие признаки, очертания и результат как, например, выход из интеграционного объединения одного или нескольких государств. При этом процесс выхода из интеграционного объединения политически не всегда значит, что выход произошел экономически. В этой связи роль таможенного обеспечения среди прочих обеспечивающих сил международной экономической интеграции сохраняется, практически становится главенствующей, центральным звеном международного сотрудничества органов государственной власти объединенных государств.

Поскольку верхние пределы международной экономической интеграции могут иметь вполне четкие очертания, то с одной стороны можно сделать вывод о том, что и рациональное экономическое поведение имеет определенные верхние пределы. Однако, следует отметить, что при достижении верхних пределов рациональное экономическое поведение может постепенно сменяться иррациональным экономическим поведением. Следствием данного процесса является то, что экономическая интеграция позднее может сменяться экономической дезинтеграцией. Данный процесс цикличен и обусловлен цикличной сменой рационального и иррационального экономического поведения, которые закономерны и сменяют друг друга в силу цикличности экономического развития объеди- няющихся или объединенных государств. Что касается смены экономической интеграции дезинтеграцией, то данный процесс более регулируемый и особую роль здесь играет таможенное обеспечение, которое способно вовремя диагностировать тенденции к иррациональному поведению, и выработать ряд мероприятий по предупреждению будущих деструктивных тенденций. В этом должна заключаться одна из основополагающих функций международного таможенного сотрудничества.

Естественное стремление к укреплению и развитию экономического потенциала на основе рационального экономического поведения становится одной из ведущих предпосылок к углублению и расширению интеграции.

Полагаясь на содержание рационализма (от лат. rationales - разумный, ratio - разум) как на систему философских направлений, которые в качестве центрального пункта анализа с субъективной стороны рассматривают разум, мышление, рассудок, а с объективной стороны - разумность, логический порядок вещей [4], следует отметить, что рациональное экономическое поведение является логической реакцией общества на ограниченность в его распоряжении различных видов ресурсов. Международная экономическая интеграция, также имеющая в качестве одних из ключевых своих целей оптимальное соотношение доходов и расходов, сбалансированное соотношение удовлетворения общественных потребностей и максимизации доходов, является выражением или формой международного рационального экономического поведения. В этой связи появление, становление международной экономической интеграции в Европе - это общественно-политический и социально-экономических процесс, во многом являющимся наследием европейского рационализма.

\section{Библиографический список}

1. Статистический словарь. М.: «Финансы и статистика», 1989. С. 301.

2. Ганзейский союз как прообраз грядущего миропорядка. // Российский совет по международным делам. Аналитические статьи. 31.12.2019 г. [Электронный ресурс]. URL: https://russiancouncil.ru/analytics-andcomments/analytics/ganzeyskiy-soyuz-kak-proobraz-gryadushchego-miroporyadka/?sphrase_id=34809503 (дата обращения 04.05.2020)

3. Словарь иностранных слов. М: «Русский язык», 1982, С. 395.

4. Философский энциклопедический словарь. М.: Изд. дом «ИНФРА-М», 1997. С. 386. 